\title{
ФАКТИЧЕСКОЕ ПИТАНИЕ ДЕТЕЙ С САХАРНЫМ ДИАБЕТОМ 1 ТИПА: ПРОБЛЕМЫ И ПУТИ РЕШЕНИЯ
}

\author{
Турчанинов Д.В., Власенко Н.Ю., Юнацкая Т.А., Павлинова Е.Б. \\ ФГБОУ ВО «Омский государственный медицинский университет» Минздрава России
}

\begin{abstract}
АКтУАЛЬНОСТЬ: в последние десятилетия в мире отмечается рост заболеваемости сахарным диабетом (СД) 1 типа среди детей и подростков. При клиническом обследовании у этих пациентов часто отмечается нарушение показателей физического развития и проявления недостатка витаминов и микроэлементов. Диетотерапия в сочетании с другими компонентами лечения СД, может улучшить клинические и метаболические показатели.
\end{abstract}

ЦЕЛЬ: гигиеническая оценка фактического питания детей с установленным диагнозом СД 1 типа.

МАТЕРИАЛЫ И МЕТОДЫ: в Исследовании приняли Участие 26 детей с СД 1 типа в возрасте 2-7 лет. Фактическое питание оценивалось частотным методом, сравнивалось с Нормами физиологических потребностей в энергии и пищевых веществах для различных групп населения РФ. Статистическая обработка с помощью пакета Microsoft Excel и Statistica 6.

РЕЗУЛЬТАТЫ И ОБСУЖДЕНИЕ: питание детей характеризовалось избыточным потреблением энергии. Медиана калорийности рациона детей 3-7 лет составила 2224,2 ккал/сут, что на 23,6\% больше нормы (1800 ккал). Потребление энергии детьми 2-3 лет было нормальным, в пределах погрешности метода, составило 1479,2 ккал/сут при норме 1400 ккал.

Отмечалось избыточное потребление белка детьми всех возрастов. Потребление белка детьми 2-3 лет составило 70,39 г/сут при норме 42 г/сут, содержание белка в рационе детей 3-7 лет составило 86,78 г/сут при норме 54 г/сут.

Питание детей являлось несбалансированным за счет избытка жиров у 88,5\% детей, при относительном недостатке углеводов у $50 \%$ исследуемых.

Медиана потребления жиров в рационе детей 2-3 лет составила 75,0 г/сут (превышение на 59,6\%), а в рационе питания детей 3-7 лет 112,59 г/сут (превышение на 87,65\%) за счет насыщенных жирных кислот (избыток у 100\% детей в возрасте 2-3 лет и у 71,4\% детей в возрасте 3-7 лет) и холестерина (избыток у 88,4\% детей). Соотношение жирных кислот семейств $\omega-6 / \omega-3$ было близко к норме и составило 10,5:1 (при рекомендуемом 10:1).

Фактическое потребление углеводов детьми 2-3 лет составило 137,6 г/сут, при рекомендуемом значении 203 г/сут (снижено на 32,2\%); фактическое потребление углеводов детьми 3-7 лет составило 235,3 г/сут при рекомендуемом значении 261 г/сут (снижено на 9,83\%). Потребление пищевых волокон было достаточным: составило 12,87 г/сут детьми 2-3 лет, при минимально необходимом 8 г/сут; детьми 3-7 лет - 18,29 г/сут при необходимом потреблении 10 г/сут.

Потребление витамина D составило 0,62 и 0,64 мкг/сут (в группах детей 2-3 и 3-7 лет соответственно), при суточной физиологической потребности для детей 2-7 лет - 10 мкг/сут, что составило всего 6,2-6,4\% от суточной потребности.

Среднесуточное потребление витамина А в рационе питания детей 2-3 лет составило 0,29 мкг рет. экв./сут (при норме 0,45 мкг рет. экв./сут), что ниже нормы на 35,5\%. Потребление фолиевой кислоты детей в возрасте 3-7 лет составило 141,49 мкг, при минимально необходимом потреблении 200 мкг (снижено на 29,25\%).

ВЫВОдЫ: Питание детей с СД 1 типа является нерациональным, несбалансированным за счет избыточного потребления жиров и относительного недостатка углеводов в рационе. Приоритетными дефицитными микронутриентами в питании детей являются витамин $D$, фолиевая кислота и витамин $A$, что требует своевременной диетической и микронутриентной коррекции.

КЛЮЧЕВЫЕ СЛОВА: сахарный диабет; дети; фактическое питание; дефичит витамина D. 